\title{
A razão/desrazão no alienista: um ensaio em literatura e psicanálise
}

\author{
Reason/unreason in alienist: an essay in literature and psychoanalysis
}

\section{Camila Backes dos Santos' e Lisiane Machado de Oliveira Menegotto}

Resumo: $\mathrm{O}$ artigo propõe-se a discutir a ficção como um importante dispositivo/analisador que lança perguntas fundamentais ao campo da psicanálise. Através da análise do conto "O alienista", de Machado de Assis, problematiza as classificações dos ditos transtornos mentais - o DSM - e a consequente fábrica de fármacos, como uma forma de redução e submissão do sujeito aos saberes ditos científicos. Simão Bacamarte surge como a figura que carrega uma visão binária e superficial sobre os caminhos da razão e da desrazão, o que se define aqui pela opção linguageira de dualismo chapado. O personagem é tomado de uma lógica paranóica ao deparar-se com as incertezas acerca da loucura, sua e do outro. O trabalho tem como objetivo, dessa forma, estabelecer uma relação entre tal característica do personagem e o conceito de fita moebiana para a psicanálise, que nos permitiu também estabelecer o que seria uma "vertigem de completude". O conto é uma obra que atravessa os tempos e produz inquietações sobre o que se acredita como certeza no campo da cientificidade. Nessa perspectiva, cabe parafrasear o autor: "Se as linhas de definição entre a razão e a desrazão estão perfeitamente delimitadas, para que transpor a cerca?"

Palavras-chave: Alienista; Psicanálise; Machado de Assis.
Abstract: The following article proposes to discuss fiction as an important device/analyzer that raises fundamental questions within the field of psychoanalysis. Through the analysis of the short story "The alienist", written by Machado de Assis, problematizes the classifications of said mental disorders - the DSM - and the consequent pharmaceutical industry, as a way of reducing and submitting the subject to the so-called scientific knowledge. Simão Bacamarte emerges as a figure that carries a binary and superficial insight of the paths of reason and unreason, which is defined here by the language option of flat dualism. The character is taken by a paranoid logic when faced with the uncertainties regarding madness, both his own and other's. This study aims, therefore, to establish a relationship between this characteristic of the character and the concept of Moebian tape for psychoanalysis, which also allowed us to establish what would be a "vertigo of completeness". The short story is a work that crosses the times and produces concerns about what is believed to be a certainty in the scientific field. In this perspective, it is appropriate to paraphrase the author: "If the lines of definition between reason and unreason are perfectly delimited, why go over the fence?"

Keywords: Alienist; Psychoanalysis; Machado de Assis.

\footnotetext{
1 Pós-doutoranda em Diversidade Cultural e Inclusão Social pela Feevale. Doutora em Psicologia Social e Institucional pela UFRGS. E-mail: camibackes@gmail.com .

2 Mestre e Doutora em Psicologia do Desenvolvimento (UFRGS), professora do PPG em Diversidade Cultural e Inclusão Social e do Mestrado em Psicologia e do Curso de Psicologia da Universidade Feevale. E-mail: lisianeoliveira@feevale.br .
} 


\section{Introdução}

0 conto "0 alienista", de Machado de Assis, foi publicado pela primeira vez na revista Papéis avulsos, no ano de 1882. No início da história, o leitor é informado que as páginas a seguir contarão a história de Dr. Bacamarte, médico que vivera em Itaguaí em tempos remotos, filho da nobreza e 0 maior médico do Brasil, de Portugal e das Espanhas. 0 rei de Portugal, não conseguindo que o médico ficasse em Coimbra, regendo a universidade, faz com que ele acabe regressando ao Brasil. Diz Bacamarte à sua Majestade:"a ciência é meu emprego único, Itaguaí, o meu universo" (Assis, 1882-2008, p. 3). 0 alienista faz de Itaguaí sua residência, na qual passa a desenvolver seu método científico de estudos e aplicações de teorias para desenvolver e defender a sua tese. Entrega-se aos "estudos da alma" de forma visceral e religiosa. 0 casamento com Dona Evarista, "a viúva sem beleza que distraísse o médico de seus propósitos, mas com boas condições fisiológicas para trazer-lhe filhos" (Assis, 1882-2008, p. 3), não Ihe trouxe nenhum, proporcionando ainda mais tempo e dedicação a seu intuito científico." "A ciência tem o inefável dom de curar todas as mágoas", (Assis, 1882-2008, p. 9) diz o narrador, e, dessa forma, Simão entrega-se cada vez mais cegamente a seu projeto de delimitar a razão da desrazão.

Simão Bacamarte afirma que"a saúde da alma é a ocupação mais digna do médico"(Assis, 1882-2008, p. 4). Mas o que seria a saúde da alma? Machado, neste momento, estava em plena consonância com as dúvidas da época que cerceavam o individualismo nascente na modernidade. Neste momento, as perguntas giravam em torno do que podia a ciência e qual seria o seu lugar na teoria do conhecimento. Gledson (1998) afirma que "0 alienista"éo lugar onde podemos procurar uma resposta às grandes questões de sua época, as quais retornarão na forma de novas perguntas. A ambição de Simão Bacamarte, diz 0 autor, leva-0 muito além daquilo que convencionalmente chamamos de loucura: seu objetivo é uma análise da mente humana. Por isso, atenta-se ao fato de esta obra machadiana ser vista como um expoente fundamental para o estudo da relação entre razão e desrazão, uma vez que se os limites estão claramente demarcados, então por que transpor, cruzar esta cerca?

Os estudiosos das psicopatologias na atualidade apontam que existe uma ala da psiquiatria que sinaliza os "limites demarcados" e procura uma forma "clara" de classificação. "Uma racionalidade diagnóstica que se contenta com o que é redutível a modalidades regulares de sintomas tenderia a expandir esse conceito de tal modo que o reencontraria em toda forma de vida" (Dunker, 2005, p. 25). Opera-se, nesse sentido, num furor sanandi, apoiado pela indústria farmacêutica, que promete a eliminação e o fim do mal-estar como se fosse esse o caminho na direção da cura ou o segredo da felicidade. Para a psicanalista Maria Rita Kehl (2011), a classificação em forma de transtornos oferecida pelo DSM (Manual Diagnóstico e Estatístico de Transtornos Mentais) no campo da psiquiatria e em vigência nos sistemas de saúde "obstaculiza qualquer tentativa de abordagem metapsicológica desta forma epidêmica de sofrimento psíquico" (DSM, 2013 p. 107). No que concerne à escuta psicanalítica, "o que diferencia um sujeito do outro não é 0 maior ou menor conhecimento do objeto do desejo, mas o compromisso - ou não - com a condição desejante, através das escolhas de vida que representam o que mais importa para cada um" (Kehl, 2011, p. 108). A experiência do sofrimento psíquico e das paixões da alma," "colocadas numa lógica discursiva, foram substituídas de forma reducionista a uma coleção de comportamentos observáveis, à catalogação de agrupamentos de sintomas clínicos que falam por si" (Sibemberg, 2011, p. 94). 0 sujeito da psicanálise éjustamente esse que é irredutível, que circula em uma experiência única e por isso sua transmissão - a transmissão da experiência - é um desafio.

Na cidade de ltaguaí,"cada louco furioso era trancado em uma al cova, na própria casa e, não curado, mas descurado até que a morte vinha o desfraldar do benefício da vida, os mansos andavam à solta pela rua" (Assis, 1882-2008, p. 19). 0 filósofo francês Michael Foucault, no livro "História da loucura", publicado originalmente em 1961, faz uma longa genealogia da loucura desde a época medieval. 0 autor faz uma contestação do internamento como única opção encontrada para lidar com a loucura e também questiona o domínio do poder médico-psiquiátrico na terapêutica da loucura. Em sua discussão sobre loucura e internamento, Foucault aponta que no final da idade média, por volta do século XV, o problema da lepra desaparece e, com isso, um vazio aparece no espaço do confinamento. Se toda a preocupação do poder real em torno do controle dos leprosos desapareceu, as reações de divisão e exclusão permaneceram. Na paisagem imaginária da Renascença, a nau dos loucos ocupava um espaço fundamental. Ela transportava tipos sociais que embarcavam em uma grande viagem simbólica em busca de fortuna e da revelação dos seus destinos e das suas verdades. Esses barcos faziam parte do cotidiano dos loucos, que eram expulsos das cidades e transportados para territórios distantes. Foucault vê, nessa circulação dos loucos, mais do que uma simples utilidade social, visando à segurança dos cidadãos e evitando que os loucos ficassem vagando dentro da cidade. Todo esse desejo de embarcar os loucos em navios simbolizava uma inquietude em relação à loucura no final da Idade Média. A partir do século XV, ela passa a assombrar a imaginação do homem ocidental e a exercer atração e fascínio sobre ele. 0 fascínio do homem pela loucura faz com que surja a necessidade de aprendê-la e assim formular um conhecimento que a torne compreensível. No conto "O alienista", a paixão pela ciência de Simão Bacamarte foi a expressão do período iluminista, que acreditava nos poderes da razão para conquistar a liberdade e a felicidade. Sua formação médica ocorreu entre o fim do século XVIII e inícios do XIX quando teve início também a Revolução Francesa e o poder exercido pelo Imperador Napoleão Bonaparte. Para Slavutsky (2010, p. 3), existe uma analogia entre os nomes Bonaparte e Bacamarte, ambos fascinados pelo poder. Seguindo a história do nome alienista, o nome Simão tem a ver com símio, macaco e também com sim e não fazendo sinão, simnão, Simão. 0 jogo dos contrastes entre a ciência e a ignorância, a razão e a loucura, o médico e o monstro autoritário, 0 que ajudou os doentes que estavam relegados na vila e 0 que os prendeu para curá-los.

Pelo domínio da razão o homem pode evoluir e progredir indo aos poucos se aperfeiçoando. Mais atualmente, o que aprendemos com Canguilhem (1966) é que não há diagnóstico sem uma concepção determinada do que vem a ser patológico e normal, sendo que o primeiro não é a simples inversão do segundo. Diante disso, o artigo objetiva estabelecer uma relação entre a visão binária e superficial, característica do personagem principal Simão Bacamarte, através da opção linguageira de "dualismo chapado", lançando mão, para isso, do conceito de fita moebiana para a psicanálise assim como o que nos permitiu refletir sobre "vertigem de completude"e o inclassificável.

\section{O dualismo chapado de Simão e a torção da fita de Moebius}

Simão Bacamarte, ao encontrar-se com os loucos de Itaguaí, produz, através da tese que tenta desenvolver, uma defesa paranoica e passa a querer dividir a cidade entre os loucos e os não loucos. Para isso constrói um asilo que 
chama de Casa Verde, por causa da cor das janelas, e passa a criar categorias e subcategorias de classificação dos ditos transtornos mentais para delimitar quem ficaria preso e quem ficaria solto. Não menos importante é destacar que, para Lanceti e Amarante (2006), "0 alienista”éa primeira obra do saber médico-psiquiátrico, em que pese o fato de ser uma obra literária e não científica.

[...] os alienados foram alojados por classes. Fez-se uma galeria de modestos, isto é, dos loucos em quem predominavam esta perfeição moral; outra de tolerantes, outra de verídicos, outra de símplices, outra de leais, outra de magnâmicos, outra de sagazes, outra de sinceros, etc. (Assis, 1882-2008, p. 43)

0 dualismo chapado se refere justamente a este ol har que tudo divide, que só enxerga dois caminhos: a razão ou a desrazão. Cada louco deve ser enquadrado em um sistema classificatório e então levado à Casa Verde. 0 dual não admite arestas, dobras ou falhas. No chapado tudo vira categoria, tudo deve se encaixar em um lugar de nomeação, não existe espaço para o duvidoso, ou para uma verdade do sujeito, tudo é uma redução das modalidades de sofrimento. 0 dual e chapado apenas permite uma distribuição binária, não opera com as profundidades da/na superfície. 0 encontro de Simão com este outro da loucura nos remete ao sentimento de Unheimlich freudiano ${ }^{3}$, onde 0 que aparece mais estrangeiro a cada um pode ser a expressão do mais íntimo, porém afastado da consciência, sob o efeito do recalque. No conto de Machado de Assis, o personagem acaba, ao final da história, por reconhecer em si a única loucura e interna-se sozinho, vindo a falecer louco e solitário na Casa Verde.

Fechada a porta da Casa Verde, entregou-se ao estudo e à cura de si mesmo. Dizem os cronistas que ele morreu dali a dezessete meses, no mesmo estado em que entrou, sem ter podido alcançar nada. Alguns chegam ao ponto de conjeturar que nunca houve outro louco, além dele, em Itaguaí, mas esta opinião, fundada em um boato que correu desde que 0 alienista expirou, não tem outra prova senão o boato; e boato duvidoso, pois é atribuído ao Padre Lopes, que com tanto fogo realçara as qualidades do grande homem. Seja como for, efetuou-se o enterro com muita pompa e rara solenidade. (Assis, 1882-2008, p. 43)

0 estranho/familiar opera em Simão Bacamarte na forma de uma visão dual e chapada, ou seja, ele não é capaz de transitar entre o dentro e o fora operando em uma torção entre os processos internos e externos. Para pensar o que vai além de uma visão dual e chapada, como a característica principal de Simão Bacamarte, podemos fazer um contraponto com o que Lacan utiliza em sua obra como a banda de Moebius, já que adentramos nesse momento no terreno das superfícies. Tal banda ou fita sugere a estrutura do inconsciente, sua superfície apresenta uma gama de fenômenos paradoxais ${ }^{4}$. Através dessa análise de superfície podemos pensar no terreno da psicanálise e do inconsciente. Para o psicanalista Marc Darmon (1994, p. 11), o inconsciente coloca em evidência o problema da topologia, questão que permaneceu não resolvida em Freud. 0 termo que se refere à psicologia das profundezas não é satisfatório, pois sugere a imagem de uma superfície com partes inferiores e compromete a técnica psicanalítica diretamente com a vida da arqueologia. Freud, ao longo da formulação da primeira tópica, dedicou-se a pensar na técnica psicanalítica, na perspectiva de conscientizar o inconscientizado, de modo a trazer à tona ou à superfície o que estaria oculto nas profundezas. Mas, o estudo sobre as resistências mais adiante, quando começa a rascunhar a segunda tópica, o faz seguir por outro caminho. A formulação do conceito de compulsão à repetição foi o que provocou uma verdadeira torção na composição metapsicológica. 0 conceito foi, inicialmente, apresentado no texto "Repetir, recordar e elaborar", em 1914 (Freud, 1914-1996b). Mais tarde, em "Além do princípio do prazer", Freud (1920-1996a) consagra a tese de que a compulsão à repetição era um princípio que antecedia o princípio do prazer, sendo condição para que este passasse a vigorar. É partir dessa guinada na metapsicologia freudiana que a repetição passa a revelar o caráter inexorável da pulsão, como algo que se impõe e insiste. Dessa maneira, o inconsciente, que outrora era situado nas camadas profundas da geografia psíquica, passa a habitar a superfície do aparelho psíquico, na medida em que pulsa e escapa aos domínios da consciência, por meio de sonhos, lapsos, atos falhos, hesitações, sintomas, chistes e da própria transferência.

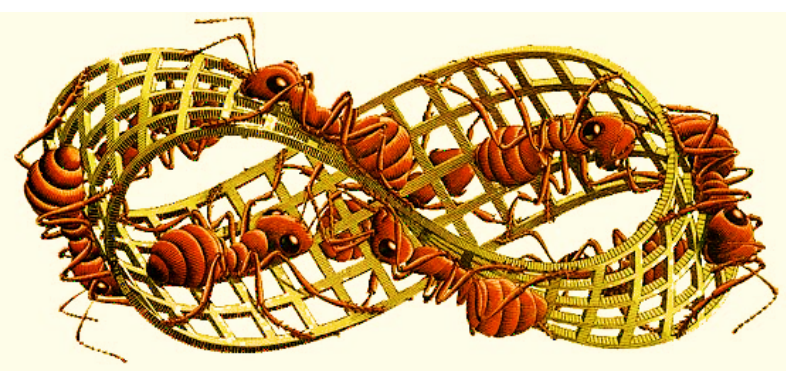

Figura 1. Fita de Moebius

Fonte: http://images.google.com.br

A banda ou fita de Moebiusé uma figura que pode ser também um objeto físico, o resultado de sua torção não é nada simples, pois contraria de muitas formas a expressão que temos de nossos objetos no cotidiano. 0 lado externo e interno, assim como o direito e avesso passam a operar em continuidade. 0 uso das duas faces, do "cara e coroa", fica invertido. Como mostra a figura acima, inspirada pelo desenho de Escher. Se uma formiga percorrer a fita, ao longo de uma volta estará no avesso do ponto de partida, e, na segunda volta estará novamente no ponto de partida, acabando por percorrer toda sua extensão. Pereira (2008, p. 19) salienta que é só o tempo que permite diferenciar 0 avesso do direito, pois eles estão separados apenas pelo tempo que leva para percorrer a fita.

A dimensão do tempo precisa fazer a entrada na dicotomia da fita, como por exemplo, na imagem acima, é necessário que a formiga complete o trajeto

\footnotetext{
3 No conceito freudiano de "estranho", este remete a um encontro com o desconhecido, o Unheimelich, que é o sujeito para ele mesmo, nas diversas formas de aparição do estranho como seu duplo. O estranho não seria algo alheio ou novo, mas algo de há muito familiar. O texto freudiano Das Unheimelich (1919), fala de uma inquietante estranheza que diz de uma relação ao simbólico enfraquecida, uma irrupção do real em sua relação com o mal-estar.

4 Para construir a fita basta tomar uma tira de papel e girá-la, através de uma operação de torção de 180 graus sobre si mesma.
} 
para que noção da subversão da superfície surja. 0 tempo é que constitui a diferença entre as faces, isso porque a banda tem apenas uma face e uma borda. Para a autora, "a existência de uma margem única é essencial, pois que uma das definições topológicas da banda se apoia justamente sobre esse paradoxo" (Pereira, 2008, p. 19). Diferente da fita euclidiana (ou de dupla face) que tem "apenas" duas faces, duas bordas, dentro e fora, interno e externo, a banda de Moebius tem uma única margem ou borda, única face, não possui interno e externo, nem dentro e fora. A formiga da imagem está simultaneamente dentro e fora, ou ainda, nem dentro e nem fora. Do mesmo modo, o inconsciente não se encontra nem no interno do corpo, em algum espaço que poderia ser mapeado neurologicamente, e nem no externo - na língua, na sociedade, na realidade sensível.

A banda de Moebius faz parte de uma área maior de estudos que se chama topologia, que integra o campo de estudo da matemática. A topologia é a ciência que estuda o espaço e as suas propriedades, de modo que seu objeto de estudo é a noção de espaço e as relações que o estabelecem. Em 1861, Augusto Moebius descobriu esta figura e por isso ela se inscreveu na história sob seu nome: banda de Moebius. A banda faz uma subversão da análise das partes por trechos da fita e faz aparecer uma outra dimensão que não comporta o todo. 0 espaço moebiano acaba por produzir um efeito paradoxal que permite uma consideração muito direta à noção de estrutura formulada por Lacan. 0 psicanalista francês utilizou a topologia como uma prática (cortar, atar, dobrar), que pode fundamentar a própria prática com 0 inconsciente estruturado como uma linguagem. Na psicanálise existe uma clivagem entre saber e verdade. Sendo assim, um significante não é o mesmo quando faz parte da cadeia do discurso consciente ou da cadeia inconsciente. Isso ocorre de forma análoga à dupla inscrição topológica da banda. Podemos conceber a cadeia inconsciente no avesso da cadeia consciente (Pereira, 2008). A unilateralidade da superfície explica que as formações do inconsciente se produzem no discurso consciente sem transpor nenhuma borda, de modo que os lapsos e os esquecimentos se produzem no interior do discurso (Darmon citado por Pereira, 2008).

As formações do inconsciente surgem no discurso consciente sem atravessar nenhum limiar, como o trajeto da formiga inspirado no desenho de Escher. Tais trajetos possibilitam situarmos alguns espaços em particular como o funcionamento do sujeito na linguagem, por exemplo. Segundo Pereira (2008), podemos considerar o fato de que algo do movimento moebiano, do sujeito na linguagem comparece não só na fala,mas também na escrita. Dessa forma, pergunta a autora, porque não poderíamos recolher alguns de seus índices também na literatura? Em sua tese de doutorado, "0 conto machadiano: uma experiência de vertigem - ficção e psicanálise", propõe que a torção da fita moebiana serviria para pensar na estrutura do conto, onde faz uma passagem no geral da literatura para o particular do conto. Pergunta-se: não seria a passagem de uma concepção do binário para a estrutura subversiva de Moebius uma via fecunda para formularmos uma contribuição a mais no pensar sobre a estrutura do conto? Se pensarmos analogicamente, o protagonista do conto não faz essa torção na superfície do sim e não, do louco e não louco, ele fica apenas na fita euclidiana, apenas em um lado ou no outro, e não em um lado e no outro. A concepção binária em Simão Bacamarte é a condição que permite questionar as linhas de tensão do campo das classificações e do mal-estar acerca da razão/desrazão.

No segundo momento do conto, opera-se uma torção, o que a autora considera como uma característica típica da obra machadiana e que pode ser relacionada à fita moebiana. A partir da leitura sobre as teses do argentino Ricardo Píglia (2004) sobre as formas do conto, defende a ideia de que a torção nos contos machadianos produzem um efeito de vertigem no leitor. A primeira tese de Píglia sugere que um conto conta sempre duas histórias. Nessa perspectiva, ele parte do exemplo de uma anedota tirada de um conto deTchekov: "Um homem em Montecarlo vai ao cassino ganha um milhão, volta para casa, suicida-se." Há uma descontinuidade abrupta na espera pela ordenação "jogar-perder-suicidar-se". Sabemos que para a psicanálise, o sujeito se encontra sempre às voltas com o real, sendo o mal-estar um de seus indícios. Para Píglia (2004, p. 89) a forma do conto está condensada nesta contramão da previsibilidade, na descontinuidade. Essa cisão paradoxal seria "a chave para definir o caráter duplo da forma do conto, que trabalha a tensão entre as duas histórias sem nunca resolvê-las" (Píglia, 2004). A sua segunda tese propõe que o conto é um relato que encerra uma história secreta. Não se trata de um sentido oculto, mas de uma história contada de modo secreto através de um efeito de surpresa, relâmpago. É neste ponto que Pereira insere um "a mais" na forma da narrativa do conto. Este um além é a banda de Moebius, figura topológica utilizada por Lacan. A partir desta assunção entre o dual e chapado de Simão e a subversão da fita, ambos concernidos com a estrutura. Esta figura se mostra interessante para esta reflexão, pois salienta justamente o enigma, o funcionamento de al go que irrompe na estrutura, o que subverte a tranquilidade linear e polarizada. A banda de Moebius é o et cetera da classificação, é a ironia do conto, a forma de trabalhar através dos enigmas.

No conto, temos vários momentos de viradas, mas em nenhum momento uma rendição do personagem à sua alienação dual. As entradas e saídas da Casa Verde não operam em um sentido de uma cura, mas apenas em um vai e vem que só aumenta com os mandos e desmandos de Simão, o que são, as saídas frustradas encontradas pela cidade de Itaguaí, para lidar com o enigma da morte e da loucura.Simão morre convicto de suas verdades, louco e só, assim como a cidade de Itaguaí. Enem mesmo a passagem do tempo ao longo da narrativa, desde sua chegada em Itaguaí, recém formado, até o momento em que se vê só na Casa Verde operam a torção da visão dual e chapada do personagem. 0 tempo, o fator decisivo para a irrupção da torção da fita moebiana e também o elemento necessário para produção do chiste, não produz nada em Simão. A ironia no conto é o que representaria a possibilidade de um sujeito resultante da dúvida, da divisão. A dúvida, ao mesmo tempo que mantém ligados e fixados, suspende os limites entre interno e externo, sujeito e objeto, interpretação e ato. A ironia opera, dessa forma, ao lado do sujeito dividido. A operação de torção na narrativa do conto pode ser representada pelo recurso irônico característico da escrita de Machado de Assis, de modo a amalgamar o trágico e o cômico.

\section{A vertigem da completude e 0 inclassificável na razão/desrazão}

Tal qual o conto nos surpreende com a torção e seu consequente efeito de vertigem no leitor como apontou Pereira (2008), podemos pensar que também o conto traz à luz uma "vertigem de completude". 0 sim e o não de Simão evidenciam toda a dificuldade de transitar por aquilo que não cabe em uma ordenação. "0 alienista" é um conto que, através da ironia, discute a questão do inclassificável. Machado de Assis mostra as dificuldades de apreensão de um saber, as tentativas frustradas do alienista de determinar as linhas que imagina delirantemente estarem tão bem demarcadas. 0 autor não 
foi o único escritor a refletir sobre as ordenações e classificações, mas talvez 0 único a levá-las para o campo da saúde mental na história do internamento da loucura no Brasil e se apropriar tão sabiamente de um mal-estar sobre este momento histórico.

A psiquiatria moderna surge no final do século XIX, momento que 0 homem passa a se questionar sobre os destinos da desrazão. Durante a Primeira Guerra Mundial, surgem importantes avanços na área da psicometria e da testagem psicológica como forma principalmente de selecionar os melhores soldados para a guerra e depois os melhores empregados para as indústrias. É assim que logo após a Segunda Guerra são classificados os primeiros transtornos mentais, divididos em retardos mentais e déficits de inteligência. Surge, então, o primeiro DSM em 1952, com 182 classificações de transtornos que compreendiam em boa parte casos clínicos representados por condições psicológicas como as neuroses (fóbica, obsessivo-compulsiva, depressiva, neurastênica, hipocondríaca ou de despersonalização) e as desordens de personalidade (paranoide, ciclotimia, esquizóide, explosiva, obsessiva-compulsiva, histérica, astênica, antissocial, passivo-agressiva, inadequada). $\mathrm{Na}$ quarta edição revisada do mesmo manual, editado em 1994, o número de transtornos subiu para 297. Ou seja, em 32 anos foram listados 115 novos transtornos, um aumento massivo de 63\% de novas categorias diagnósticas. Na edição de 2013, o DSM-V, já contava com mais de 600 tipos de classificações dos transtornos mentais!

Machado de Assis, mesmo sem saber, faz uma ode ao et cetera da classificação. E o que isto quer dizer? Georges Perec, escritor e poeta francês que fez parte do Oulipo, um grupo que fazia experimentações com a forma da linguagem, desenvolve uma instigante teorização sobre os sistemas de classificação. Em"penser/claser"Evidencia"o quão tentador éo afã de distribuir o mundo inteiro segundo determinados códigos capazes de reger o conjunto dos fenômenos, embora saibamos que lamentavelmente não funciona, nunca funcionou, nunca funcionará" (Perec, 2003, p. 90). Perec reconhece o furor das classificações e trabalha literária e artisticamente na composição de sua crítica. Admitir tal instabilidade, no entanto, segundo Perec, "não nos impedirá que sigamos durante muito tempo classificando os animais pelo seu número ímpar de dedos ou por seus chifres ocos"(p. 90). A necessidade de classificar, agrupar, catalogar, agrupar etc. sempre acompanharam o nosso ol har para o mundo e são imperativos para nossa necessidade de fixar as ordens que nos permitem sobreviver ao caos da multiplicidade e da diversidade (Maciel, 2009, p. 17).

Perec (2003), em seu livro, faz um inventário de possíveis critérios taxonômicos (alguns bastante absurdos) para a organização de sua biblioteca. 0 autor lista e categoriza diferentes modos de disposição dos livros nas estantes, chegando à conclusão de que toda a biblioteca se organiza a partir de uma combinação de todos esses modos. 0 que, em sua conclusão, não garante uma classificação satisfatória de todos os volumes, visto que, segundo ele, "em torno de três-quartos dos livros nunca foram realmente classificados" ( Perec, 2003, p. 40).

Mas porque estes três-quartos de livros nunca foram classificados? Podemos pensar que seja porque seriam difíceis de ordenar ou porque seriam impossíveis de classificar (Maciel, 2009, p. 17). Assim, o autor cria uma nova categoria para estes livros, a do et cetera. Tal categoria também foi usada por Jorge Luís Borges em seu famoso ensaio "0 idioma analítico de John Wilkins", no qual o escritor argentino propõe uma enciclopédia chinesa que classifica os animais do mundo em doze categorias insólitas e irônicas, ordenadas no esquema do abecedário, em que o et cetera se insere precisamente na categoria
L, vindo ainda não ao final da categorização, mas antes das últimas duas categorias, garantindo ainda mais estranhamento ao leitor (Borges, 1999). Assim, cabe aqui a seguinte pergunta: seria o et cetera o furo na classificação que rodeia todo o conto machadiano através do recurso irônico? Captar o conceito de ironia causaria mal-estar aqueles que tentassem the impor um núcleo unificador, pois muito mais que um recurso, a ironia é percebida como uma atitude. A ironia poderia até mesmo ser considerada mais radicalmente como a própria essência do ato literário. A ironia neste conto de Machado opera através da identificação que é produzida pelo leitor no momento que interpreta o texto que lê. Interpretar um texto é fundamentalmente poder identificar-se com ele em algum ponto, assim como na fita moebiana autor e leitor imiscuem-se. 0 valor da literatura está justamente na relação dialógica que ela proporciona por envolver o sujeito e as experiências que o constituem.

A ironia sugere, assim, como uma outra interpretação a partir da escolha pelo ponto de identificação do leitor. A identificação não se situa nem no autor nem no interlocutor, mas no terceiro ausente, é na produção da ausência que o chiste tem seu efeito. Freud, no texto sobre o chiste e sua relação com o inconsciente aponta este como resultante tanto do sentido sexual quando do agressivo. 0 chiste pressupõe três elementos: 0 autor do chiste, 0 interlocutor e um terceiro suposto (ausente) de quem o chiste trata. Assim, a ironia na produção machadiana aqui estudada atuou na produção de uma desestabilização das dualidades.

A vertigem da completude é, portanto, a tentativa (sempre fracassada) de ordenar 0 et cetera da classificação. 0 et cetera é a categoria que falta, que não faz a ordem com as demais, e seria por excelência a categoria que falta a todos os sistemas taxonômicos em geral? No conto machadiano encontramos um campo fértil para uma análise do mal-estar referente a uma busca inapreensivel de um lugar de nomeação. O lugar que Simão busca desesperadamente ordenar é o inconsciente. Eeste lugar surge da subversão da fita, o personagem é dual e chapado e por isso não subverte o espaço, não há espaço para uma assunção do inconsciente na teoria da mente humana do alienista. 0 conto surge como um retrato caricatural dos limites da apreensão de um saber, uma trama na qual a representação da ciência acaba perdendo-se nas suas próprias certezas. Apreender aquilo que é inapreensível é o caminho mais curto para um lugar sem saída. Acompanhemos essa tese nas palavras de Machado de Assis, pela fala do Vigário Lopes: "Com a definição atual, que é a de todos os tempos, acrescentou, a loucura e a razão estão perfeitamente delimitadas. Sabe-se onde uma acaba e outra começa. Para que transpor a cerca?" (Assis, 1882-2008, p. 14). Ainda, segue o personagem Simão no conto:

0 principal nesta minha obra da Casa Verde é estudar profundamente a loucura, os seus diversos graus, classificar-Ihes os casos, descobrir enfim a causa do fenômeno e o remédio universal. Este é o mistério do meu coração. Creio que com isto presto um bom serviço à humanidade. (Assis, 1882-2008, p. 14)

Neste ponto, perguntamo-nos: o que aí nos interroga? Equal o estranhamento que tal trecho nos produz? É dessa forma, que, numa lógica que beira 0 absurdo, o personagem vai segmentando a razão da desrazão. Apontamos que Freud, ao incluir o conceito de inconsciente à sua abordagem, subverteu radicalmente a oposição normal e patológico. Talvez, pela dificuldade de enxergar aquilo que the é estranho e ao mesmo tempo familiar, o personagem, imbuído da lógica paranóica, torna-se um retrato daquilo que não aceita a 
divisão, e, frente à condição do mal-estar, engendra um caminho sem lugar para dúvidas, situando-se num lugar de alienista/alienação.

Pergunta-se sobre este saber, sobre onde acaba e onde começa a razão humana. Seria possível traçar tal linha? Sem querer propor um diagnóstico ao nosso personagem Simão, pensamos na relação deste como análoga ao mal-estar referente ao ser no mundo. Sabemos que o campo da psicopatologia, na contemporaneidade ocidental, vem cada vez mais em direção à lógica de classificação dos ditos "transtornos mentais", nos quais cada qual pode encontrar-se e ajustar-se a um quadro sindrômico, descrito, mais recentemente, pela última versão do DSM, de 2013. Numa perspectiva positivista e biomédica, 0 DSM opera, não raras vezes, como um hegemônico e inexorável dispositivo de classificação e controle, reduzindo o sofrimento humano a uma concepção calcada na medicalização.

Assim, perguntamo-nos se seria essa busca por formas delimitadas de classificar a mente humana uma tentativa de traçar a linha para não ter que se haver com este imenso litoral que é a existência e a falta de verdades? Não à toa que recorremos à expressão litoral, uma vez que ela exprime um encontro sempre impreciso entre o mar e a areia.

\section{Considerações finais}

Para Freud, a literatura faz parte obrigatória da formação do psicanalista porque está antecipa muitas vezes os achados clínicos, possuindo profundo conhecimento sobre o humano. Na releitura freudiana Lacan irá dizer que são os discursos os discursos que não ensinam a sofrer a amar e aborda muitas vezes a literatura clássica na sua obra. Acolhe-se aqui a ideia da ficção, dessa forma, como aquela que traduz o mal-estar das subjetividades e a forma que o humano engendra para lidar com a situação de desamparo, que lhe é inerente. Segundo Freud (1930), no texto "0 mal-estar na cultura", a posição de fragilidade estrutural do sujeito estaria relacionada a três causas: na relação do homem com a sua corporeidade, que tende à decadência pela passagem inevitável do tempo, nas ameaças imprevisíveis e impiedosas da natureza e, por fim, a causa da maior fragilidade do homem: os horrores gerados nas relações ambivalentes com os outros.

O sujeito é, assim, desamparado por vocação. Freud, nesse sentido, lança o sujeito num mundo sem Deus, neste, com efeito, nem mesmo a crença no ideal da felicidade - possibilitado pela ciência no discurso do lluminismo - é reconhecida. Freud enuncia que a felicidade jamais poderia ser alcançada por uma fórmula universal - como teria preconizado o discurso da ciência, que prometeu bem-estar para todos - mas apenas de maneira singular, que seria possibilitada pela economia pulsional. Seria justamente por isso, aliás, que existiria o mal-estar na cultura. Para Freud, cultura é tudo aquilo que difere 0 homem da vida animal, é o controle do homem sobre a natureza, ou seja, é tudo aquilo que corresponde, na verdade, ao processo de modernização do social que se realizou no Ocidente desde então, de maneira que a ideia de um mal-estar na cultura deve ser interpretada como uma crítica à modernidade.

Diante do desamparo primordial que tange o sujeito, podemos pensar nos diferentes destinos que cada um engendra em sua experiência particular. Conseguir permanecer e suportar a dor provocada pela posição de desamparo é o grande desafio colocado para o sujeito em uma análise, por exemplo. Enunciar a posição radical do sujeito, no limite do desamparo seria outra maneira de formular o efeito da experiência de castração. Porém, colocado nessa posição limite, entre a vida e a morte, o sujeito pode construir efetivas possibilidades de sublimação e de criação, pela construção de uma forma singular de existência e de um estilo próprio para habitar seu ser. Machado de Assis dinamita, com sua ironia perspicaz, um modo de refugiar-se nos saberes classificatórios criados pela fatalidade determinista.

Em"0 alienista", temos uma forma de desmoralizar saberes e instituições, de maneira irreverente e gozadora, o que se salienta também através das reticências e no magnetismo das sugestões que se refere ao leitor. Percebemos no conto um "suicídio lógico da razão". Simão Bacamarte recolhido por sua própria vontade à Casa Verde representa o próprio suicídio do determinismo cientificista, que, na sua caça das verdades, acabou, por fim, reconhecendo em si mesmo a fatalidade do erro.

Nas palavras de Augusto Meyer (2005, p. 37):"Cai - portanto a lógica do absurdo - e nunca o riso de Machado de Assis foi mais feroz, mais consciente e mais voluptuoso". A Casa Verde foi o hospício criado pelo eminente doutor Simão Bacamarte, para onde se dirigiam em algum momento, todos os personagens, e que, ao lado de seu fundador, representava os mecanismos classificatórios do cientificismo da época e que se renovam e se perpetuam, tornando a obra atemporal. Ao tratar ironicamente de tal universo, o conto traz uma filosofia com um profundo senso do relativo: nada é absoluto, nada merece amor ou ódio. No vai e vem das internações na Casa Verde, circulavam as posições de saberes, sendo que em nenhum momento se encontra, ao longo da trama, um lugar de verdade. Nessa perspectiva, não habitar o lugar da verdade era o que parecia ser insuportável para o personagem Simão.

Por isso, podemos pensar que a subversão da superfície chapada ficaria por conta da ironia do conto (o efeito de obliquidade tão caro a Machado de Assis), que opera transpondo os limites entre o interno e externo. Entendemos a ficção, assim, como uma forma de lidar com e apontar as impossibilidades que a necessidade da referência ao inconsciente coloca para os humanos. A ficção não presta conta às verdades daquilo que diz, mas fala dos enigmas das verdades. 0 mal-estar de um contexto foi o enigma apontado por Machado de Assis, que conseguiu, talvez mesmo sem que ele próprio soubesse, assim como ocorre em qualquer processo de escrita, lançar luz sobre as sombras do nosso contemporâneo. Uma atualidade na qual, como afirma Dunker (2008), a redução das modalidades de sofrimento a uma mesma gramática normativa e a uniformização dos sintomas neutralizam justamente o potencial crítico que estes possuem de produzir novas modalidades de laços sociais.

\section{Referências}

American Psychiatric Association. (2013). Diagnostic and Statistical Manual of Mental Disorders, Fifth Edition (DSM-V). Arlington, VA: American Psychiatric Association.

Assis, M. de. (1882-2008). 0 alienista. Porto Alegre: L\&PM.

Borges, J. L. (1999). Obras completas. Rio de Janeiro: Globo. 4v.

Canguilhem, G. (1966-1990). Onormal e o patológico. Rio de Janeiro: Forense Universitária.

Darmon, Marc. (1994). Ensaios sobre a topologia lacaniana. Porto Alegre: Artes Médicas.

Dunker, C. (2005). Mal-estar, sofrimento e sintoma: uma psicopatologia do Brasil entre muros. São Paulo: Boitempo.

Foucault, M. (1997). História da loucura na Idade Clássica. São Paulo: Perspectiva.

Freud, S. (1996a). Além do princípio de prazer. In Edição standard brasileira das obras psicológicas completas de Sigmund Freud (Vol. 18, pp. 13-75). Rio de Janeiro: Imago. (Trabalho original publicado em 1920) 
Freud, S. (1930-1996b). 0 mal-estar na civilização. In Edição standard brasileira das obras psicológicas completas de Sigmund Freud (Vol. 21, pp. 73-148). Rio de Janeiro: Imago

Freud, S. (1914-1996c). Recordar, repetir e elaborar. In Edição standard brasileira das obras psicológicas completas de Sigmund Freud (Vol. 12, pp. 161-171). Rio de Janeiro: Imago.

Gledson, J. Contos: uma antologia - Machado de Assis. São Paulo: Companhia das Letras, 1998.

Kehl, M. R. (2011). A atualidade das depressões (como pensar as depressões sem 0 DSM IV). In A. Jerusalinsky, \& S. Fendrik, S. (Orgs.), o livro negro da psicopatologia contemporânea (pp. 103-130). São Paulo: Via Lettera.

Lancetti, A., \& Amarante, P. (2006). Saúde Mental e Saúde Coletiva. In G. W. S. Campos et al., Tratado de Saúde Coletiva (pp. 615-634). São Paulo: Fiocruz.

Maciel, M. E. (2009). As ironias da ordem: coleções, inventários e enciclopédias ficcionais. Belo horizonte: Editora UFMG.

Meyer, A. (2005). Machado de Assis. Porto Alegre: Instituto Estadual do Livro: Corag.

Perec, G. (2003). Penser/Classer. Paris: Seuil.

Pereira, L. (2008). O conto machadiano: uma experiência de vertigem - ficção e psicanálise. Rio de Janeiro: Nazar.

Pereira, M. E. C. (2008). Pânico e desamparo: um estudo psicanalítico. São Paulo: Escuta.

Piglia, R. (2004). Formas breves. São Paulo: Companhia das Letras.

Sibemberg, N. (2011). Autismo e psicose infantil: o diagnóstico em debate. In A. Jerusalinsky, \& S. Fendrik (Orgs.), o livro negro da psicopatologia contemporânea (pp. 93-102). São Paulo: Via Lettera.

Slavutsky, A. (comunicação pessoal, 2006). Sobre "O alienista": o herói da casa verde. Ciclo de Debates Machado de Assis na Cultura: Psicanálise e Literatura. Porto Alegre. 